\title{
BLOOD FLOW AND OVARIAN RESPONSE AFTER THE USE OF SHORT-TERM PROTOCOL TO SYNCHRONIZE OVULATION IN GOATS
}

\author{
M.A. Abdel-Ghani ${ }^{1 *}$, T.M. El-sherry ${ }^{1}$, M. Hayder ${ }^{2}$, N. Abou-Khalil ${ }^{3}$, F. Abou Ammou ${ }^{2}$, M. El- \\ Shafie $^{2}$, T. Abdel-khalek ${ }^{2}$, H. Hamdon ${ }^{4}$ \\ ${ }^{1}$ Department of Theriogenology, Faculty of Veterinary Medicine, Assuit University, Assuit, 71526, Egypt , ${ }^{2}$ \\ Animal Production Research Institute, Agriculture Research Center, Dokki, Giza,12311, Egypt , ${ }^{3}$ Faculty of \\ Medicine, Assiut University, Assuit, 71526, Egypt, ${ }^{4}$ Animal Production Dept., Faculty of Agriculture, Assiut \\ University, New Valley Branch, El kharga, New Valley, 3201, Egypt. \\ *Correspondence: M.A. Abdel-Ghani (e-mail: mohammed_ali76@hotmail.com)
}

\section{SUMMARY}

This study was designed to investigate the relationship between progesterone (P4), estradiol (E2), nitric oxide (NO), and blood flow (BF) of ovarian follicle after estrous synchronization in Sa'idi goats. Thirty goats were injected with $P G F 2 \alpha$, then immediately after they received an intravaginal Progestagen impregnated sponge for 5 days. At the time of sponge removal, the goats were divided into two groups; group 1 was injected with PMSG and group 2 was injected with GnRH. The day of Progestagen withdrawal was considered as Day 0.Arbitrary-scale, blood flow area (BA) and blood flow area percent (BA\%) were used to assess the follicle blood flow (FBF) in color Doppler images. The results showed that follicular wave emergence occurred in $P M S G$ group significantly earlier $(P<0.05)$ than in GnRH group. There was a significant difference between groups $(P<0.001)$ and group by day interaction $(P<0.001)$ in $B A$ and BA\%. The P4 and E2 levels showed an effect of group $(P<0.001)$ and effect of group by day interaction $(P<0.001)$. The NO revealed only a significant difference between group by day interaction $(P<0.001)$. The increase in E2 was associated with a marked increase in NO and follicular growth. In both groups, P4 was negatively correlated with NO; however, the E2 and BF were positively correlated with NO. All correlations were significant $(P<0.0001)$. The data of the present study, concluded a positive correlation between E2, NO and BF in goats.

\section{Keywords: Blood flow, Follicles, Nitric oxide, Sa'idi goats}

\section{INTRODUCTION}

Goats were the first species domesticated by human for the production of milk, meat, and skin as well as for the production of fiber (Boyazoglu et al., 2005). The physiological differences between the breeding and the anestrus seasons necessitate the use of different techniques for the control of estrus during each period. Furthermore, the expanded popularity of meat goat production has led to increased interest in reliable methods to synchronize/induce estrus in goats. With estrus synchronization, producers are able to be more efficiently using complementary techniques for reproductive management, including AI and embryo transfer, so that genetic material is more easily obtained or transferred domestically and internationally (Whitley and Jackson 2004).
Color Doppler ultrasonography is a useful, noninvasive technique for evaluating ovarian vascular function, allowing a visual observation of the blood flow in the wall of follicles (Brannstrom et al., 1998) and corpus luteum (Acosta et al., 2003). This image has facilitated hemodynamic studies and reproducible measurements (Acosta et al., 2005). The use of color Doppler ultrasonography to investigate the ovarian responses after hormonal stimulation has been recently studied in ovine (EL-Sherry et al., 2013), horses (Witt et al., 2012) and cows (Matsui et al., 2009). In addition, Doppler sonography has been successfully used to study ovarian blood flow during the IVF cycle in human (Tarlatzis et al., 2003; Honnensa et al., 2009) and cows (Bo et al., 2008), 
and it was found to be correlated with the subsequent ovarian response (Honnensa et al., 2009).

Nitric oxide (NO) is a potent vasodilator agent that is involved in folliculogenesis and ovulation (Tamanini et al., 2003). NO stimulates the synthesis of both PGE and PGF2 $\alpha$ that cause inflammation in the pre-ovulatory follicle and induce rupture (Faletti et al., 1999) with other locally produced substances, growth factors and cytokines (Tamanini et al., 2003).

To our knowledge, there is no available data about the changes of the follicular blood flow in Sa'idi goats and its relationship with the serum progesterone (P4), estradiol-17 $\beta$ (E2) and NO concentrations. Therefore, the objective of the current study was to characterize the changes in the blood flow (BF) and its relationship with changes in P4, E2, and NO within the ovulatory follicle after short-term progesterone based synchronization protocols in Sa'idi goats.

\section{MATERIAL AND METHODS}

\section{Animals and management:}

Adult female goats $(\mathrm{n}=30)$ with age $(1.5-3$ years $)$ and weight (20-23 Kg) were selected from the lot maintained at Mallawi Animal Production Research Station, El-Minia, Egypt, (latitude $28^{\circ} 07^{\prime} \mathrm{N}$ and $30^{\circ} 33^{\prime} \mathrm{E}$ ) during the first 3 weeks of October (Autumn). The Sa'idi goats are a local Egyptian breed found in the southern part of the country. The animals were kept mainly for meat production. The goats were maintained on graze in pens during all the day. Water and a mineral supplement were available ad libitum. The management of the goats did not change throughout the experimental period. The bucks were separated from goats.

\section{Experimental design and measurements:}

The goats were randomly divided into two equal groups, and were registered by attaching numbers on their ears. Prostaglandin is able to synchronize estrus by inducing the regression of the corpus luteum (CL) when it was present. The progesterone has an inhibitory effect on the release of $\mathrm{LH}$ and FSH. Therefore, once removal of progesterone sponge, the release of FSH and LH occurred that were necessary for initiation of estrous cycle.

Group 1 (PGF2 $\alpha$-short-term progestagen treatment-PMSG): the animals received an intravaginal Progestagen impregnated sponge (40 mg fluorogestone acetate, GFA, Chronogest ${ }^{\circledR}$, Intervet,
International, boxmeer, Netherland) for 5 days, and were injected with $2.5 \mathrm{mg}$ of Dinoprost (Lutalyse, Pfizer manufacturing, Purts, Belgium) at the time of sponge insertion. At the time of sponge removal, 500 IU PMSG (Folligon, Intervet) was injected.Group 2 (PGF2 $\alpha$-short-term progestagen treatment-GnRH): the animals received an intravaginal Progestagen impregnated sponge for 5 days, and were injected with $2.5 \mathrm{mg}$ of Dinoprost at the time of sponge insertion. At the time of sponge removal, $10.5 \mu \mathrm{g}$ busereline acetate (GnRH, Receptal, Intervet) was injected.

Administrated hormones that were used for the estrus synchronization were made between 18:00 and 19:30 $\mathrm{h}$ in all groups. Starting at the first hour of removal of the intravaginal sponges in all groups, the occurrence of behavioral estrus signs was monitored every $4 \mathrm{~h}$ interval and for $5 \mathrm{~d}$ using teaser bucks $(n=5)$. The goats were considered to be in estrus only if they stood while being mounted by the bucks. Duration of estrus was defined as the interval between the onset and end of estrus signs. The end of estrus was the time when the doe refused to be further mounted. The day of Progestagen with drawal was considered as Day 0.

The reproductive parameters determination following the treatment according to Simoes et al. (2006), were as follows:

* Onset of estrus (interval from sponge's removal to time of first estrus detection).

* Estrus response (number of goats showing estrus/total number of goats treated in each group $\mathrm{X}$ 100).

* Onset of follicular wave: First observation of at least one follicle $\geq 3 \mathrm{~mm}$ diameter, followed by a growing follicular wave resulting in a follicle with a minimal diameter of $5 \mathrm{~mm}$.

* Day of maximum follicular diameter: The first day when the dominant follicle reached its maximum diameter (greater than $5 \mathrm{~mm}$ ).

* End of follicular wave: The day when the number of follicles $<3 \mathrm{~mm}$ was increased and the number of follicles $\geq 3 \mathrm{~mm}$ was decreased by the same proportion.

* Duration of wave: Interval between the onset and the end of a follicular wave.

\section{Doppler ultrasound monitoring of follicular development:}

Ultrasound scanning was performed by the same operator every $24 \mathrm{~h}$ until ovulation, using a Doppler 
ultrasound scanner (Mylab30, Piemedical, Netherlands), equipped with a 6-8 $\mathrm{MHz}$ endo-rectal linear probe (Lv513). Examinations were conducted on the standing goat. The urinary bladder was used as a guide to find the uterine horn. The probe was rotated laterally $90^{\circ}$ clockwise and $180^{\circ}$ anticlockwise to scan the ovaries and genitalia. The size and number of follicles was detected and profiled by retrospective evaluation of ovarian sketches that provided topographical and the diameter changes for each follicle. The follicular dynamics and ovulation rate were recorded. Following morphological evaluation of the ovarian findings, the power flow mode of the ultrasound scanner was activated for blood flow mapping. Color signals were used to evaluate the blood flow around the entire perimeter of the follicle.
The sectional area (SA) of the follicle was estimated by the following equation $\mathrm{SA}=\pi / 4^{x} \quad(\mathrm{SD})^{2}$, where $\mathrm{SD}$ is the sectional diameter. The colored areas in the image that existed at the maximum diameter of the follicle were used as a quantitative index to express the blood flow within the follicular wall (Fig. 1). Areas of color represent regions with flow velocity higher than $0.08 \mathrm{~m} / \mathrm{s}$ called blood flow area (BA), while blood flow area percent $(\mathrm{BA} \%)$ was used to show the relation between $\mathrm{BA}$ to the follicle $\mathrm{SA}$ and estimated by the following equation $\mathrm{BA} \%=\mathrm{BA} / \mathrm{SA} \times$ 100. Recorded images and videos were stored on a USB Flash Drive. The sectional areas were calculated and the blood flow areas (BA) were quantified using Image J program (version 1.62) developed at the USA National Institute of Health (http://rsb.inf.nih.gov/ij).
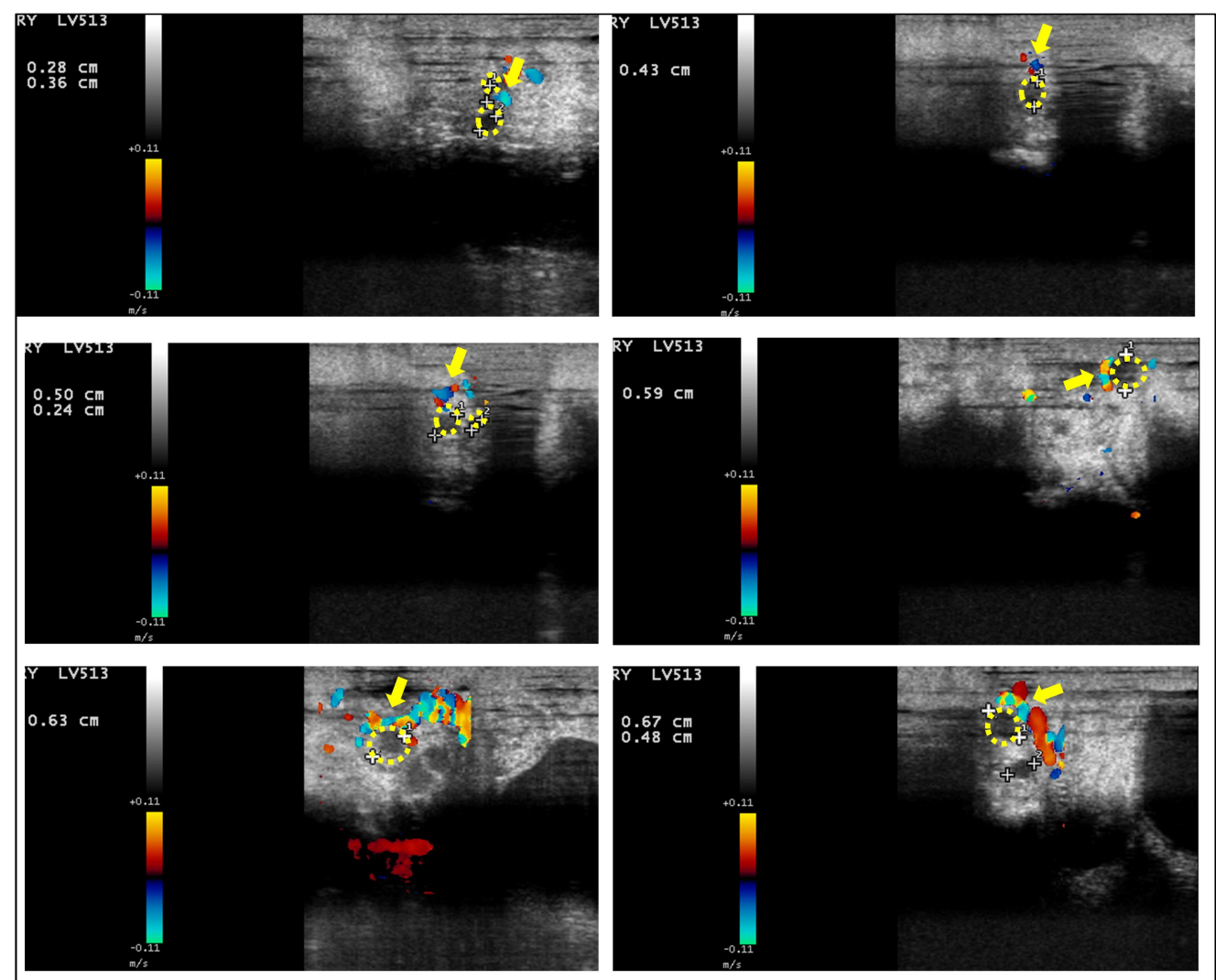

Fig. 1. Color Doppler images of the blood flow area (BA) (yellow arrows), arbitrary blood flow score and follicular diameter. The images showing a gradual increase in the BA and intensity of arbitrary blood flow as the ovulation approaches, and were associated with the increase in the follicular diameter. 
An arbitrary-scale was used to assess the follicular blood flow in Doppler image. The scale was scored according to Oliveira et al. (2014): (0) non-detectable, (1) small, (2) moderate, (3) intense blood flow.

\section{Blood collection and hormonal determination:}

The blood samples were collected from the entire animals that were used in the experiments $(n=30)$ via jugular venipuncture Days $-5,-2$, and 0 (sponge removal), and then daily just after each Doppler scan until Day 4. At Day 0, the blood samples were collected daily for 4 days just after each Doppler scan. Samples were allowed to clot at room temperature, were centrifuged within half an hour after collection and then were stored at $-20^{\circ} \mathrm{C}$ hormones. Circulating concentrations of P4 and E2 were determined by ELISA kits (BioChek, Inc., Foster City, CA 94404, USA). NO was analyzed by Colorimetric Determination of Nitrite (Biodiagnostic, catalog No. TA2532, Egypt). The final products of NO in vivo are nitrite $\left(\mathrm{NO}_{2}\right)$ and nitrate $\left(\mathrm{NO}_{3}\right)$. There is an exogenous source of $\mathrm{NO}_{3}$ from the diet, so the index of $\mathrm{NO}$ production is the $\mathrm{NO}_{2}$. The biodiagnostic nitrite assay kit provides an accurate and convenient method for measurement of endogenous nitrite concentration as indicator of endogenous NO production in biological fluids. It depends on adding griessreagents, which convert nitrite into a deep purple azo compound, in acid medium, and in the presence of nitrite, the formed nitrous acid diazotise sulfanilamide and the product coupled with N-(1-naphthyl) ethylenediamine. The resulting azo dye has a bright reddish-purple color with an O.D. that measured at $540 \mathrm{~nm}$ when using the maximum amount of sample for the nitrite assay $(100 \mu \mathrm{l})$; the detection limit is 2.5 $\mu \mathrm{M}$.

\section{Statistical analysis:}

The P4, E2, NO and the BF were analyzed by repeated measure with time interaction using analysis of variance (ANOVA) to determine main effects of group or group by day. When main effect of group or group by day was observed, the differences of group means at specific time point were analyzed by the Student's t-test using JMP statistical software (version 5.1; SAS Institute, Cary, NC, USA). Graphpad Prism v5 software (Graphpad Software, Inc., San Diego, CA) was used to draw the figures. The different means were significant at $\mathrm{P}<0.05$ and $\mathrm{P}<0.01$. The data were expressed as mean $\pm \mathrm{SD}$. To analyze the relation between the NO and other parameters, a linear regression relationship has been used.

\section{RESULTS}

Characterization of reproductive performance and follicular growth:

The onset of heat in PMSG group started significantly shorter $(\mathrm{P}<0.05)$ than in GnRH group $(27.1 \pm 5.5 \mathrm{~h} v s .34 .3 \pm 8.9 \mathrm{~h})$, however, the duration of heat in PMSG group was significantly longer $(\mathrm{P}<$ $0.05)$ than in GnRH group $(47.4 \pm 20.6 \mathrm{~h}$ vs. $13.7 \pm$ 13.8 h) (Table 1).

Table 1. Means $\pm \mathrm{S}$.E of reproductive performances in Sa'idi goats after PGF2ashort-term progesterone treatment (5 days of intravaginal Progestagen impregnated sponge). Associated with 500 IU of PMS (PMS group), or $10.5 \mu \mathrm{g}$ of busereline acetate (GnRH group) at the time of sponge withdrawal

\begin{tabular}{lcc}
\hline Reproductive performances & PMSG group & GnRH group \\
\hline Estrus response (\%) & $15 / 15(100 \%)$ & $12 / 15(80 \%)$ \\
Onset of heat (h) & $27.1 \pm 5.5^{\mathrm{a}}$ & $34.3 \pm 8.9^{\mathrm{b}}$ \\
End of heat (h) & $74.6 \pm 17.6^{\mathrm{a}}$ & $48.0 \pm 12.2^{\mathrm{b}}$ \\
Duration of heat (h) & $47.4 \pm 20.6^{\mathrm{a}}$ & $13.7 \pm 13.8^{\mathrm{b}}$ \\
Onset of the wave (d) & $0.6 \pm 0.5^{\mathrm{a}}$ & $1.3 \pm 0.5^{\mathrm{b}}$ \\
First day of maximum follicular diameter & $4.1 \pm 0.3^{\mathrm{a}}$ & $3.4 \pm 0.5^{\mathrm{b}}$ \\
Growing phase (d) & $3.7 \pm 0.9^{\mathrm{a}}$ & $2.0 \pm 0.6^{\mathrm{b}}$ \\
Maximum follicular diameter (mm) & $6.3 \pm 0.6$ & $6.0 \pm 0.6$ \\
End of wave (d) & $4.9 \pm 0.3^{\mathrm{a}}$ & $3.4 \pm 0.6^{\mathrm{b}}$ \\
Length of wave (d) & $4.3 \pm 0.7^{\mathrm{a}}$ & $2.6 \pm 0.5^{\mathrm{b}}$ \\
\hline
\end{tabular}

${ }^{\mathrm{a}-\mathrm{b}}$ within a rows, means without a common superscript differed $(P<0.05)$. 
The follicular wave emergence occurred in PMSG group $(0.6 \pm 0.5 \mathrm{~d})$ earlier $(\mathrm{P}<0.05)$ than in GnRH group $(1.3 \pm 0.5 \mathrm{~d})$. The day of maximum follicular diameter and end of wave were, respectively, $4.1 \pm 0.3$ and $4.9 \pm 0.3 \mathrm{~d}$ for PMSG group and $3.4 \pm 0.5$ and $3.4 \pm 0.6 \mathrm{~d}$ for $\mathrm{GnRH}$ group $(\mathrm{P}<$ 0.05). The length of the growing phase of the dominant follicle in GnRH group $(2.0 \pm 0.6)$ was lower $(\mathrm{P}<0.05)$ than in PMSG group $(3.7 \pm 0.9 \mathrm{~d})$. Thus, the length of wave for PMSG group (4. $3 \pm 0.7$ d) was longer $(\mathrm{P}<0.05)$ than for $\mathrm{GnRH}$ group (3.4 \pm 0.6$)$.

The diameter of recruited follicles was $2.9 \pm 0.2$ $\mathrm{mm}$ for PMSG group and $2.4 \pm 0.3 \mathrm{~mm}$ for $\mathrm{GnRH}$ group. In PMS group, the maximum follicular diameter was $6.3 \pm 0.6 \mathrm{~mm}$, and $6.0 \pm 0.5 \mathrm{~mm}$ in $\mathrm{GnRH}$ group. There was no significant difference (P
$>0.05)$ between the two groups in the size of recruited and ovulatory follicles (Figure 2A).

\section{Blood flow profile:}

Arbitrary blood flow scores increased from Day 0 to Day 4 in both groups (Figure 2B). PMSG group had greater $(\mathrm{P}<0.05)$ blood flow scores than $\mathrm{GnRH}$ group on Day 1; however, the GnRH group had greater $(\mathrm{P}<0.05)$ blood flow scores than $\mathrm{PMSG}$ group on Day 2.

There was a significant difference between groups $(\mathrm{P}<0.001)$ and group by day interaction $(\mathrm{P}<0.001)$. In both groups, the $\mathrm{BA}$ and $\mathrm{BA} \%$ increased gradually from Day 0 till Day 4.The BA and $\mathrm{BA} \%$ were higher $(\mathrm{P}<0.05)$ in $\mathrm{GnRH}$ group $(10.3$ $\pm 1.1 \mathrm{~mm}^{2}$ and $32.3 \pm 1.5 \%$ respectively) compared with PMS group $\left(6.3 \pm 1.4 \mathrm{~mm}^{2}\right.$ and $22.7 \pm 1.7 \%$ respectively) on Day 2 (Figure 3 ).

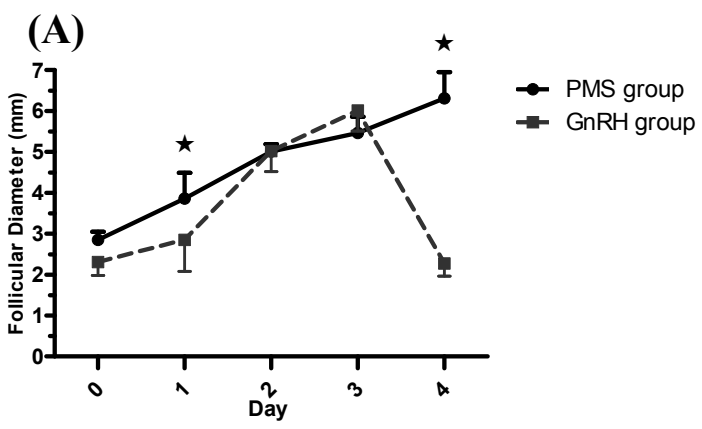

(B)

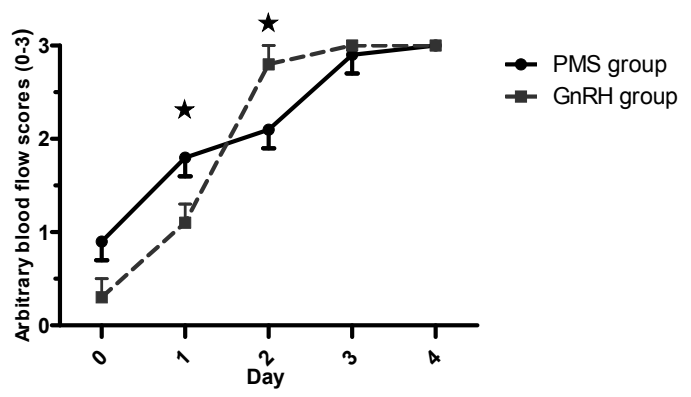

Fig. 2.Mean \pm SD. (A) The changes in diameter of the ovulatory follicle in PMSG group and GnRH group.(B) Arbitrary blood flow scores in PMSG group and GnRH group. The scale was scored accordingly to Oliveira et al (2014): (0) non-detectable, (1) small, (2) moderate, (3) intense blood flow. Differences $(\mathrm{P}<\mathbf{0 . 0 5})$ between the two groups were denoted by *
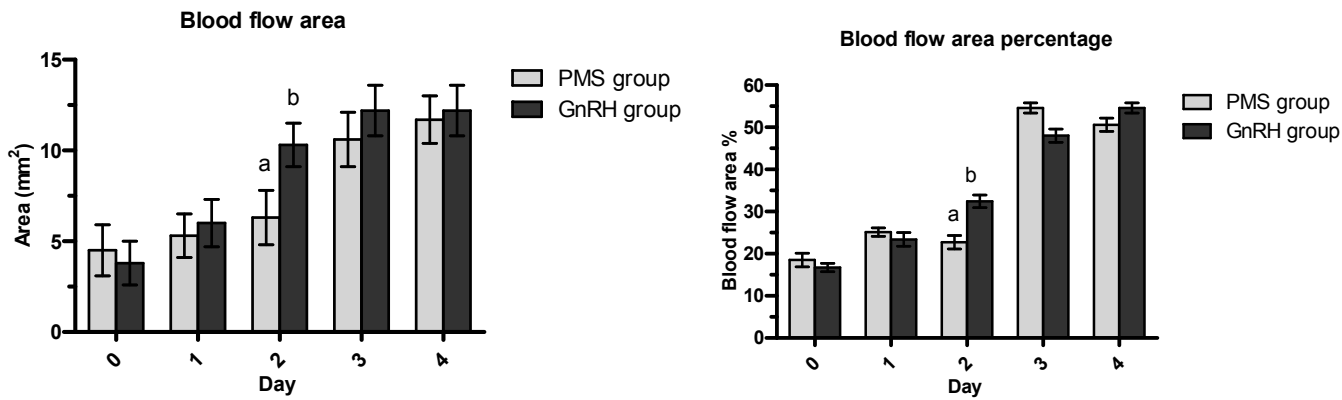

Fig.3. Summary of changes in the blood flow area (BA) and blood flow area \% (BA \%) (Mean \pm SD).Different superscripts ${ }^{\text {a-b }}$ indicate the differences between the two groups are significantly different; $\boldsymbol{P}<0.05$ 


\section{Hormonal profile:}

The P4 level was affected by group $(\mathrm{P}<0.001)$ and group by day interaction $(\mathrm{P}<0.001)$ (Figure 4A). The level of P4 in GnRH group was higher than PMSG from Day -5 to Day 1 then both groups had almost the same level until Day 4(Figure 4A). On Day 0 , the concentration of $\mathrm{P} 4$ was greater in $\mathrm{GnRH}$ group $(\mathrm{P}<0.05)$ than in PMS group.

The level of E2 from Day -5 to Day 4 was affected by group $(\mathrm{P}<0.001)$ and group by day interaction $(\mathrm{P}<0.001)$ (Figure 4B). In both groups, the E2 was increased gradually from Day 0 . The level E2 in PMSG group was higher than in GnRH group. At day 4, a sudden decrease in E2 level in GnRH group was noticed. The concentration of E2 was significantly greater $(\mathrm{P}<0.05)$ in $\mathrm{PMSG}$ group $(64.0$ $\pm 6.6 \mathrm{pmol} / \mathrm{l})$ ) than in GnRH group $(12.5 \pm 3.7$ $\mathrm{pmol} / \mathrm{l}$ ) on Day 4 (Figure 4B).

The results of NO from Day -5 to Day 4 showed that there was only significant differences between group by day interaction $(\mathrm{P}<0.001)$. In both groups, the NO was increased gradually from Day -5 until Day 3. The level in PMSG group was higher than in GnRH group at Day 2 and 3 (Fig 4C).

In PMSG group, P4 concentrations were negatively correlated with NO $(r=-0.61$, $\mathrm{P}<0.0001)$. The $\mathrm{E} 2$, follicular diameter and $\mathrm{BF}$ were positively correlated with NO $(r=0.80, \mathrm{P}<0.0001 ; r$ $=0.74, \mathrm{P}<0.0001 ; r=0.49, \mathrm{P}<0.0001$, respectively). Similarly, in GnRH group, E2, follicular diameter and BF were positively correlated with NO. The values of correlation coefficients were respectively $0.73 ; 0.84(\mathrm{P}<0.0001) ; 0.85(\mathrm{P}<0.0001)$.

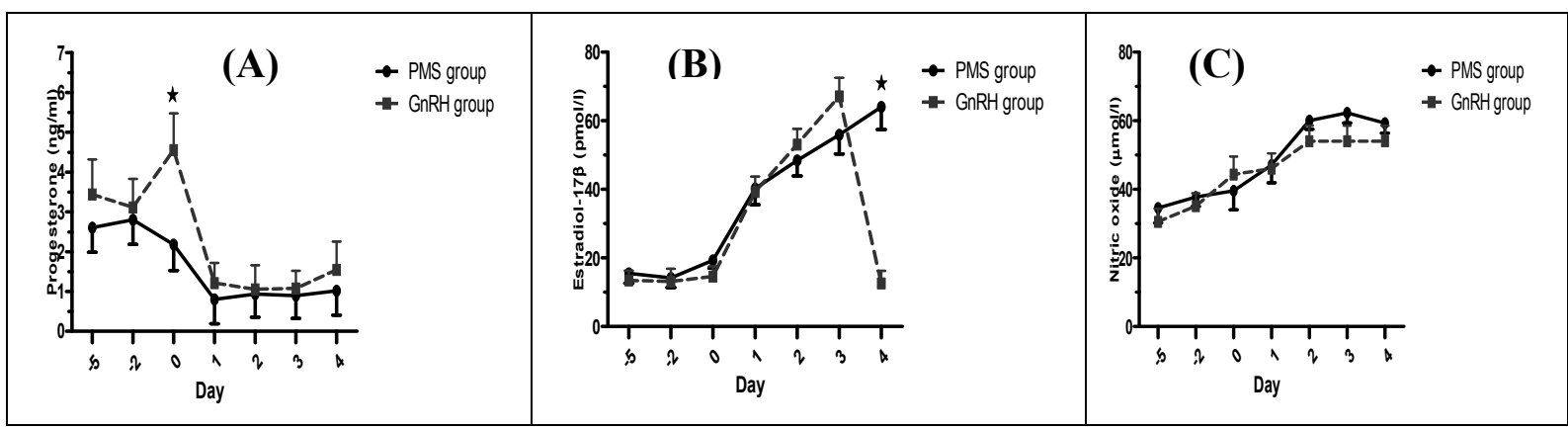

Fig. 4.Changes in plasma progesterone (P4) concentration (A), Estradiol-17ß (B) and Nitric oxide (C). Differences $(P<\mathbf{0 . 0 5})$ between the two groups were denoted by *.

\section{DISCUSSION}

In the present study, the onset of heat in PMSG group was significantly shorter than that in GnRH group after synchronization. Therefore, the PMSG reduced the interval between sponge removal and onset of estrus. Similarly, Regueiro et al. (1999) showed that the use of 500 IU PMSG decreased the interval to estrus onset in Saanen, Nubian and crossbreed goats. However, Ustuner et al. (2007) reported that there was not significant effect of the type of progestagen sponges or time of PMSG administration on the time to estrus onset in ewes.

PMSG is a long acting follitropin activity that has high sialic acid content, resulting in a long circulatory half-life (approximately 2 days) when administered in cattle (Menzer et al., 1979). GnRH has a short half-life of approximately 2-4 min due to rapid cleavage by peptidases (Conn and Crowely, 1994; Wetsel et al., 2002).
PMSG is well known to stimulate the formation of a large pre-ovulatory follicle that, because of its FSH-dependent maturation, is widely used in ovarian stimulation for assisted reproduction techniques (Vegetti et al., 2006). Moreover, PMS stimulates estradiol production via granulosa cells, which positively regulates the surge mode that triggers ovulation (Baruselli et al., 2004). However, GnRH stimulates the release of follicle-stimulating hormone (FSH) and luteinizing hormone (LH) from the pituitary gland for ovulation induction (Crowley et al., 1980). Considering that, the onset of heat and the follicular wave emergence occurred earlier in PMSG group than in GnRH group. Furthermore, the sudden decrease in E2 concentrations of the GnRH group on Day 3 likely indicates the ovulation occurred, and subsequently the end of the heat and shorter wavelength.

In the current study, there was a relationship between the follicular growth and BF, whereas, the 
$\mathrm{BA}$ and $\mathrm{BA} \%$ increased as the follicular diameter was increased. The increased $\mathrm{BF}$ to the follicle resulted in increasing the follicular vascularization and permeability of blood vessels that are known to allow a greater supply of growth factors, gonadotropins, and dissolved oxygen important to the growth of follicles resulted in follicular progression, follicular fluid production and antrum formation (Van den Hurk and Zhao, 2005) and subsequent ovulation. Thus, this may explain why BA and BA\% was increased in GnRH group compared to PMS on Day 2 as ovulation occurred earlier in GnRH group. In addition, differences in follicular diameter and blood flow seem to be related to asynchrony of ovulation moment between experimental groups, which can be estimated by follicle diameter and E2 concentration data.

Furthermore, the marked increase in ovarian BF was associated with the increase of E2, NO and follicular growth. In contrary, the low level of NO and E2 accompanied with smaller follicular diameter and lower BF. In addition, there was a positive correlation between $\mathrm{NO}$ and E2 and BF.E2 is recognized as the follicular growth, differentiation, and survival factor, which enhances aromatase activity, promotes expression of $\mathrm{LH}$ receptors, and increases sensitivity of granulosa cells to FSH and LH (Quirk et al., 2004) .NO is a potent vasodilator agent that is involved in folliculogenesis and ovulation (Tamanini et al., 2006). El-Sherry et al. (2013) demonstrated that follicular estradiol enhanced NO production, and may cause a rapid dilation of blood vessels by activating angiogenic factor such as endothelial nitric oxide synthase (eNOS). The eNOS is involved in follicular and luteal angiogenesis through the production of NO (Grazul-Bilska et al., 2006). Furthermore, the vasculature, capillary area density, and capillary number density were positively correlated with NO production (Moonmanee et al., 2013). Hence, the increase in $\mathrm{BA}$ and $\mathrm{BA} \%$ was accompanied with the increase in concentration of $\mathrm{NO}$ and $\mathrm{E} 2$ that is associated with the increase in follicular diameter. Moreover, because the granulosa layer has no blood vessels (Redmer and Reynolds, 1996), the eNOS were not detected in the granulosa layer of all follicles (Moonmanee et al., 2013) that may give an explanation for why the $\mathrm{BF}$ was absent or reduced in recruited follicle and before theca layer formation as shown in figure 2 .
Moreover, there were prominent changes in the regional blood flow of the follicle with a marked increase of the flow to the base of the follicle and a concomitant decrease of blood flow to the apex before ovulation. Thus, a blood flow determination of follicles was useful for detection and prediction of ovulatory follicle.

In conclusion, knowing the relationship between ovarian changes and blood flow parameters may be useful in the clinical management of reproductive performances and early detection of follicular responses. In addition, there is a positive correlation between $\mathrm{E} 2$, NO and BF in goats.

\section{REFERENCES}

Acosta, T.J., K.G. Hayashi, M. Ohtani and A. Miyamoto, 2003. Local changes in blood flow within the preovulatory follicle wall and early corpus luteum in cows. Reproduction 125: 759767.

Acosta, T.J., N. Yoshizawa, M. Ohtani and A. Miyamoto 2002. Local changes in blood flow within the early and midcycle corpus luteum after prostaglandin $\mathrm{F} 2$ _ injection in the cow. BiolReprod, 66: 651-658.

Baruselli, P.S., E.L. Reis, M.O. Marques and L.F. Nasser, G.A. Bo, 2004.The use of hormonal treatments to improve reproductive performance of anestrous beef cattle in tropical climates. Anim. Reprod. Sci., 82: 479-486.

Bo, G.A., D.C. Guerrero and G.P. Adams. 2008. Alternative approaches to setting up donor cows for super stimulation. Theriogenology 69: 8187.

Boyazoglu, J., I. Hatziminaoglou and P. MorandFehr 2005. The role of the goat in society: Past, present and perspectives for the future. Smal. Rum. Res., 60: 13-23.

Brannstrom, M., U. Zackrisson, H. Hagstrom, B. Josefsson, P. Hellberg, S. Granberg, W. Collins and T, Bourne, 1998. Preovulatory changes of blood flow in different regions of the human follicle. Fertil and Steril, 69: 435-442.

Conn, P.M. and W.F. Jr. Crowley, 1994. Gonadotropin-releasing hormone and its analogs. Annu. Rev. Med., 45: 391-405.

Crowley, W.F. Jr and J.W. McArthur, 1980. Stimulation of the normal menstrual cycle in Kallman's syndrome by pulsatile administration 
of luteinizing hormone-releasing hormone (LHRH). J. Clin. Endocrinol. Metab., 51: 173198.

EL-Sherry, T.M. , R. Derar and R. Bakry, 2013. Changes in blood flow in ovine follicles and serum concentration of estradiol 17 beta (E2) and nitric oxide (NO) around the time of ovulation in Ossimi ewes Anim. ReprodSci, 138: 188- 193.

Faletti, A., S. Perez Martinez, C. Perotti and M.A. de Gimeno, 1999. Activity of ovarian nitric oxide synthase (NOs) during ovulatory process in the rat: relationship with prostaglandins (PGs) production. Nitric Oxide 3: 340-347.

Grazul-Bilska, A.T., C. Navanukraw, M. L. Johnson, D.A. Arnold, L.P. Reynolds and D.A. Redmer. 2006. Expression of endothelial nitric oxide synthase in the ovine ovary throughout the estrous cycle. Reproduction 132: 579-587.

Honnensa, A., H. Niemann, K. Herzog, V. Paul, H.H.D. Meyer and H. Bollwein, 2009. Relationships between ovarian blood flow and ovarian response to eCG-treatment of dairy cows. Anim. Reprod. Sci. 113: 1-10.

Matsui, M. and A. Miyamoto, 2009. Evaluation of ovarian blood flow by colour Doppler ultrasound: practical use for reproductive management in the cow. Vet J 181, 232-240.

Menzer, C. and D. Schams, 1979. Radioimmunoassay for PMSG and its application to in vivo studies. J. Reprod. Fertil. 55: 339-345.

Moonmanee, T., C. Navanukraw, S. Uriyapongson, A. Kraisoon, S. Aiumlamaic, S. Guntaprom, T. Rittirod, P.P. Borowicz and D.A. Redmer, 2013. Relationships among vasculature, mitotic activity, and endothelial nitric oxide synthase (eNOS) in bovine antral follicles of the first follicular wave. Dome Anim. Endocrinol. 45:11-21.

Oliveiraa, M.E.F., M.A.R. Felicianoa, C.C. D'Amatoa, L.G. Oliveiraa, S.D. Bicudob, J.F. Fonsecac, W.R.R. Vicentea, E. Viscod and P.M. Bartlewskid, 2014. Correlations between ovarian follicular blood flow and superovulatory responses in ewes. Anim. Reprod. Sci. 144: 30- 37.

Quirk, S.M., R.G. Cowan, R.M. Harman, C.L. Hu, and D.A. Porter, 2004. Ovarian follicular growth and atresia: the relationship between cell proliferation and survival.J AnimSci 82, E40E52.

Redmer, D.A. and L. P. Reynolds, 1996 Angiogenesis in the ovary. Rev. Reprod., 1, 182-192.

Regueiro, M., R.P. Clariget, A. Ganzábalb, M. Aba and M. Forsberg, 1999. Effect of medroxyprogesterone acetate and eCG treatment on the reproductive performance of dairy goats. Small. Rum. Res. 33: 223-230.

Sim̃oes, J., J.C. Almeida, R. Valentim, G. Baril, J. Azevedo, P. Fontes and R. Mascarenhas 2006. Follicular dynamics in Serrana goats. Anim. Reprod. Sci., 95: 16-26.

Tamanini, C., G. Basini, F. Grasselli and M. Tirelli, 2003: Nitric oxide and the ovary. J AnimSci81, $1-7$.

Tarlatzis, B.C., L. Zepiridis, G. Grimbizis and J. Bontis 2003. Clinical management of low ovarian response to stimulation for IVF: a systematic review. Hum. Reprod. Update 9: 6176.

Ustuner, B., U. Gunay, Z. Nur and H. Ustuner, 2007. Effects of long and short-term progestagen treatments combined with PMSG on oestrus synchronization and fertility in Awassi ewes during the breeding season. Acta. Vet. Brno., 76: 391-397.

Van den Hurk R. and J. Zhao, 2005. Formation of mammalian oocytes and their growth differentiation and maturation within ovarian follicles. Theriogenology, 63: 1717-1751.

Vegetti, W. and F. Alagna, 2006. FSH and folliculogenesis: from physiology to ovarian stimulation. Reprod. Biomed Online, 12: 684694.

Wetsel, W.C. and S. Srinivasan, 2002. Pro-GnRH processing. Prog. Brain Res., 141: 221-241.

Whitley, N.C. and D.J. Jackson, 2004: An update on estrus synchronization in goats: A minor species. J. Anim. Sci., 82 (Suppl E), 270-276.

Witt, M.C., H. Bollwein, J. Probst, C. Baackmann, E.L. Squires and H. Sieme, 2012. Doppler sonography of the uterine and ovarian arteries during a superovulatory program in horses. Theriogenology, 77: 1406-1414. 


\section{ACKNOWLEDGMENT}

This study was kindly supported by project of Introducing Improved Genotypes and better managements to increase small ruminant roles in conventional Egyptian farm as an investment or income pattern. Grant No: 416 B

\section{تدفق الدموى والاستجابة الهرمونية بعد استخدام بروتوكول قصير المدى لتنظيم التبويض فى الماعز} محمد على عبد الغنى'، تيمور الثيرى'، محمد حيدر'، ناصر ابو خليل"، فاتن فهمى ابو عموّ، محمد حسن الثافعى'، طارق

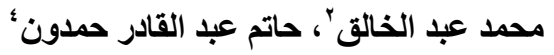

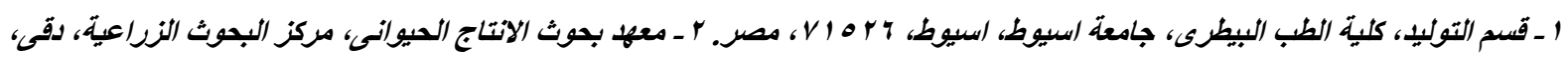

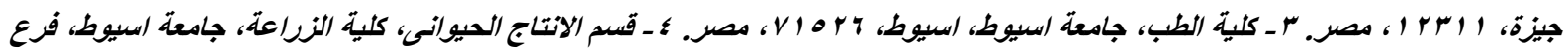

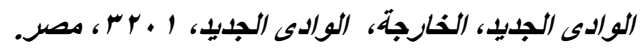

يهدف البحث لدراسة العلاقة بين هرمون البروجسترون وهرمون الاستر ادايول وأكسيد النيتريك والتدفق الدموى فى الحويصلات القابلة

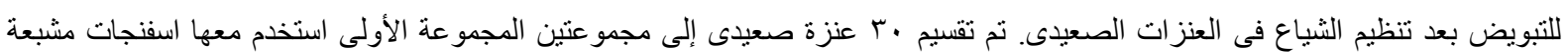

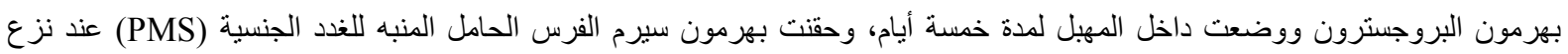

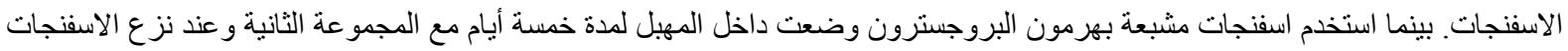

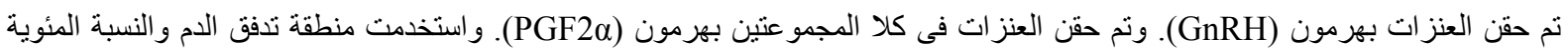

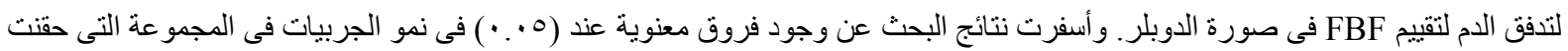

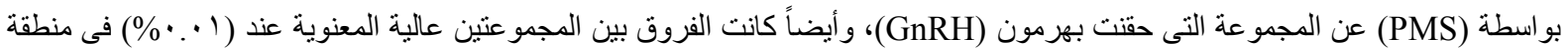

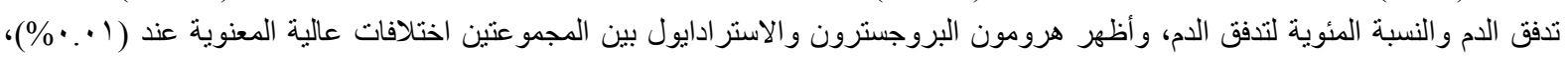

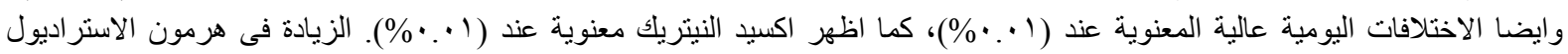

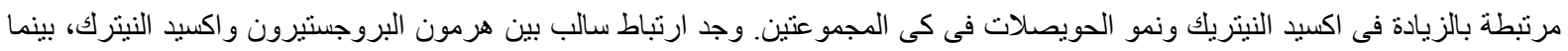

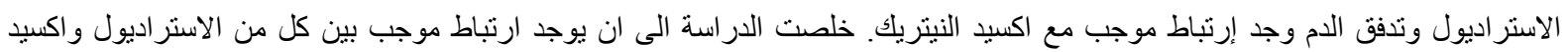
النيترك و تدفق الدم. 